\title{
The Association Between Overactive Bladder and Falls and Fractures: A Systematic Review
}

\author{
Shelagh M. Szabo (D) - Katherine L. Gooch • David R. Walker • \\ Karissa M. Johnston · Adrian S. Wagg
}

Received: July 17, 2018 / Published online: September 25, 2018

(C) The Author(s) 2018

\section{ABSTRACT}

Introduction: Urinary symptoms are associated with an increased risk of falls, but few studies have focused on patients with overactive bladder (OAB). This study aimed to synthesize estimates of the risk of falls and fractures in patients with $\mathrm{OAB}$.

Methods: Medline, EMBASE, the Cumulative Index to Nursing and Allied Health Literature, and Scopus were systematically searched for observational studies that focused on patients with $\mathrm{OAB}$. When available, data from a non$\mathrm{OAB}$ comparison sample were included. Double

Enhanced digital features To view enhanced digital features for this article go to https://doi.org/10.6084/ m9.figshare.7067429.

Electronic supplementary material The online version of this article (https://doi.org/10.1007/s12325018-0796-8) contains supplementary material, which is available to authorized users.

S. M. Szabo $(\bowtie) \cdot$ K. M. Johnston

Broadstreet Health Economics and Outcomes

Research, Vancouver, Canada

e-mail: sszabo@broadstreetheor.com

K. L. Gooch · D. R. Walker

Astellas Pharma Global Development, Inc.,

Northbrook, IL, USA

A. S. Wagg

University of Alberta, Edmonton, Canada independent review and data extraction were performed. Falls and fractures data were summarized by unadjusted and adjusted risks, and percent attributable risk (PAR) of falls and fractures associated with $\mathrm{OAB}$.

Results: Fifteen studies were included in the analyses. The proportion of patients with $\mathrm{OAB}$ experiencing at least one fall over a year ranged from $18.9 \%$ to $50.0 \%$, and the proportion of patients with $\mathrm{OAB}$ experiencing recurrent or serious falls ranged from $10.2 \%$ to $56.0 \%$. In studies that included a non-OAB comparison sample, a higher risk of falls was observed in patients with $\mathrm{OAB}$ compared to those without. A significantly increased (1.3- to 2.3-fold) adjusted OAB-associated risk of falls was reported, while unadjusted PARs for OAB associated falls ranged from $3.7 \%$ to $15.5 \%$. Risk was higher among women and those 65 years of age or older. While analysis of fractures showed elevated point estimates, most studies were underpowered to detect a statistically significant difference between groups.

Conclusions: Evidence from the published literature clearly demonstrates the importance of $\mathrm{OAB}$ and its symptoms as risk factors for falls and fractures.

Funding: Astellas.

Keywords: Accidental falls; Fractures, bone; Overactive; Review; Urinary bladder; Urology 


\section{INTRODUCTION}

Falls and fractures are important causes of morbidity and mortality among older adults (65 years of age and older), with one-third experiencing a fall annually, and approximately $10-20 \%$ of falls resulting in serious injury or fracture [1]. Unintentional injuries are the fifth leading cause of death among older adults and falls are responsible for two-thirds of deaths resulting from unintentional injuries [2]. Furthermore, fatal and non-fatal falls represent a substantial burden on healthcare resources; in 2015 , the total medical costs to treat falls in adults at least 65 years of age in the USA was estimated to exceeded $\$ 50$ billion [3]. As such, considerable effort has gone into identifying risk factors for falls, injurious falls, and fractures, and numerous modifiable and non-modifiable risk factors have been identified [4].

Overactive bladder $(\mathrm{OAB})$ is a clinically defined symptom complex consisting of urinary urgency, with or without urgency incontinence, usually with frequency and nocturia, in the absence of significant urological pathology [5]. Some of these symptoms (urgency, urgency incontinence, and nocturia) are established risk factors for falls and fractures [1, 6, 7]; however, few studies examining the risk of falls and fractures have looked specifically at patients with OAB. Published estimates of the risk of falls or fractures associated with $\mathrm{OAB}$ or its symptoms vary, ranging from $17.7 \%$ (for injurious falls from a large US survey of predominantly females, aged 54 years of age and older) [8] to up to $43.2 \%$ per year (in a small study of older Japanese women) [9]. Variability across studies is likely due to the design features of the studies, as well as the risk factor profile of study participants. Regardless, the available evidence suggests that there is an increased risk associated with $\mathrm{OAB}$, compared to the known risk of falls or fractures among the general older adult population [2].

Chiarelli et al. explored the association between urinary incontinence and risk of falls in community-dwelling adults aged 65 years and older in a systematic review that reported that urgency urinary incontinence was associated with a 1.54-fold increased risk of falls [10]. However, this study considered only selfreported falls (rather than fractures, or falls identified from medical records) and was limited to articles up to 2008 [10]. A more recent review conducted by Noguchi et al. examined the risk of falls and fractures among community-dwelling older men with lower urinary tract symptoms (LUTS), including urgency, frequency, nocturia, and incontinence, and reported a 1.31 - to 1.67 -fold increased relative risk of falls [11]. Neither of these studies specifically examined the risk profile of individuals with self-reported or diagnosed OAB.

Understanding falls and fractures risk among those with $\mathrm{OAB}$, compared to other causes of urinary incontinence, is important for several reasons. First, given that anticholinergic agents (some of which are the mainstay of pharmacological treatment for $\mathrm{OAB}$ ) are associated with an increased risk of adverse health outcomes, including the risk of falls [12-16], the risk-benefit profile of $\mathrm{OAB}$ patients (in terms of falls and treatment) warrants examination. Second, it is conceivable that the underlying central pathophysiology contributing to $\mathrm{OAB}$ could also contribute to falls risk, which is supported by the systematic review conducted by Chiarelli et al. [10].

A comprehensive and formal synthesis of available evidence on the association between $\mathrm{OAB}$ and falls and fractures has not previously been conducted [17]. The primary objective of this study was to synthesize estimates of the risk of falls, serious or recurrent falls, and fractures among individuals with idiopathic OAB, compared to those without. As a sensitivity analysis, the same outcomes were examined among patients with OAB-related symptoms or LUTS.

\section{METHODS}

\section{Search Strategy}

To meet the study objectives, a systematic literature search was conducted in multiple databases, including Scopus, PubMed/Medline, EMBASE, and Cumulative Index to Nursing and 
Allied Health Literature. The design and implementation of the subsequent systematic literature review was guided by PICOS (Population, Interventions/Comparators, Outcomes, Study design) criteria to identify observational studies reporting rates of falls, recurrent falls, serious falls, or fractures among adults with OAB (Supplementary Table 1) published between January 1985 and February 2018 (Supplementary Table 2). The databases were also searched for the most recent year's conference abstracts. Abstracts where no full manuscripts were available were similarly assessed against the PICOS criteria for inclusion. The reference lists of all included articles were searched for additional references meeting inclusion criteria.

Two researchers independently reviewed all potentially eligible abstracts and full-text publications against the PICOS criteria to identify articles for inclusion, with any discrepancies resolved through consensus. Articles that focused on individuals with diagnosed $\mathrm{OAB}$ (or urgency urinary incontinence) were included in the core analyses. To capture studies that reported on OAB symptoms, but that did not classify individuals with diagnosed $\mathrm{OAB}$, studies of individuals with incontinence or LUTS, as a proxy for diagnosed $\mathrm{OAB}$, were included in sensitivity analyses. Articles that reported non$\mathrm{OAB}$ comparison groups were also included. Articles and abstracts were excluded if the sample was restricted to those with a specific non-urological diagnosis (e.g., cancer), non-idiopathic $\mathrm{OAB}$, or institutionalized individuals (where comorbidity burdens would differ from the community-dwelling population).

\section{Data Extraction}

Data from eligible articles underwent double data extraction, performed using a customized Microsoft ${ }^{\circledR}$ Excel $^{\circledR}$ workbook. Study characteristics included authors, year, study design, as well as inclusion and exclusion criteria and follow-up period. Patient characteristics included age, sex, treatment status (if available), and the number (\%) experiencing falls or fractures.

On the basis of data provided in the original publications, persons who had fallen were categorized according to whether they experienced any fall (at least one fall), recurrent falls (at least two falls), or serious falls (falls that were injurious or required medical attention) over the follow-up period.

Study quality was assessed using the Strengthening the Reporting of Observational Studies in Epidemiology (STROBE) checklist for observational studies [18]. A summary of the STROBE assessment is in Supplementary Table 3.

\section{Data Analysis and Evidence Synthesis}

Fall and fracture risk estimates from those with diagnosed $\mathrm{OAB}$ or from the non-OAB comparison samples were graphed and visually compared. Adjusted and unadjusted risk estimates were summarized by ranges and scatterplots to explore between-study variability and stratified by mean age and sex distribution of the sample. Note, as individual fall risk factors except age and sex were inconsistently reported across studies, only age and sex were used as stratification variables in the analyses.

Estimates of increased risk of falls or fractures, as the unadjusted percent attributable risk (PAR), were calculated by subtracting the percentage without $\mathrm{OAB}$ who experienced a fall from the percentage with $\mathrm{OAB}$ who experienced a fall from the same studies. Unadjusted PARs were summarized graphically.

This article is based on previously conducted studies and does not contain any studies with human participants or animals performed by any of the authors.

\section{RESULTS}

\section{Search Results}

Of 783 unique, potentially relevant studies identified, 690 were excluded at abstract review (88.1\%; Fig. 1), and 59 of the remaining 93 $(63.4 \%)$ were excluded in full-text review. Nine additional references were identified from hand-searching, resulting in 43 eligible studies. Of these, 15 contributed estimates for the core 


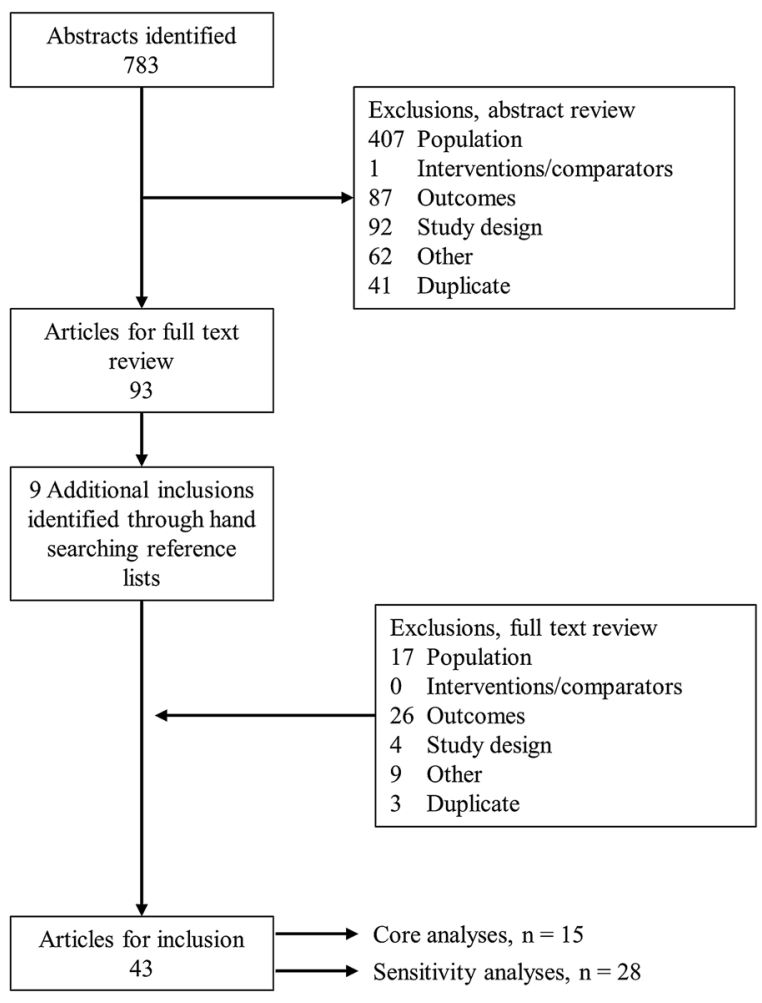

Fig. 1 PRISMA diagram for study inclusion

analyses of $\mathrm{OAB}$ patients $[6,8,9,12,19-29]$, and the additional 28 studies contributed only to the sensitivity analyses of individuals with incontinence or LUTS [1, 7, 30-54]. Overall, the included studies were in line with the STROBE criteria reporting recommendations; however, few studies provided details on how the sample sizes were determined, potential biases, or the generalizability of the findings (Supplementary Table 3).

\section{Study Characteristics}

Of the 15 studies contributing data for the core analysis, nine (60.0\%) reported outcomes among participants with $\mathrm{OAB}$, and six (40.0\%) among those with urgency incontinence (Supplementary Table 4). Nine studies (60.0\%) measured falls and fractures prospectively, and six $(40.0 \%)$ measured these retrospectively. Five studies reported on samples from the USA; two studies each from Finland, Japan, and Australia; and one study each from Canada, the UK,
Taiwan, and Korea. While 12 studies estimated risks of falls or fractures among OAB vs. nonOAB samples, three compared outcomes within treated OAB samples. Duration of follow-up ranged from 1 month to 3 years. Among the 28 studies included in the sensitivity analysis, 14 $(50.0 \%)$ measured falls and fractures prospectively, and 14 (50.0\%) measured these retrospectively. Additional characteristics of studies included in the sensitivity analysis are presented in Supplementary Table 5.

\section{Risk of Falls or Fractures}

Nine studies reported unadjusted estimates of the risk of any fall, or serious or recurrent falls, among those with $\mathrm{OAB}$ compared to those without $\mathrm{OAB}$, and one of those studies [9] reported two sets of estimates (for any fall and for recurrent falls) $[6,8,9,12,19,23-25,29]$. The absolute risk of falls in $\mathrm{OAB}$ patients was generally higher among samples of $\mathrm{OAB}$ patients who were older, or included a higher proportion of women, and from studies reporting on any fall rather than serious or recurrent falls (Fig. 2). Estimates of the percentage experiencing any fall over a year ranged from $18.9 \%$ from a cross-sectional study of 941 Japanese residents 40 years of age and older residing in two municipalities [6] to $50.0 \%$ among community-dwelling women attending a geriatric health facility in Japan [9]. Estimates of the percentage experiencing recurrent or serious falls ranged from $11.3 \%$ in a sample of Medicare enrollees (mean age, 78 years; $57.4 \%$ female) over 3 years for serious falls [29] to $56.0 \%$ from a US-based retrospective claims analysis of patients with at least 1 year of follow-up and a mean age of 73 years [12]. Unadjusted PAR for any fall associated with $\mathrm{OAB}$ ranged from $3.7 \%$ to $15.5 \%$ (both over 1 year), and for recurrent or serious falls it ranged from $4.4 \%$ to $8.8 \%$ (Fig. 3 ). Two studies estimated the risk of falls or fractures associated with $\mathrm{OAB}$ treatment. One study by Gomes et al. reported that the risk of serious falls among individuals with $\mathrm{OAB}$ treated with two different antimuscarinics was similar $(0.8 \%$ for tolterodine vs. $0.7 \%$ for oxybutynin) [20]. In the other study, the unadjusted PAR for any 


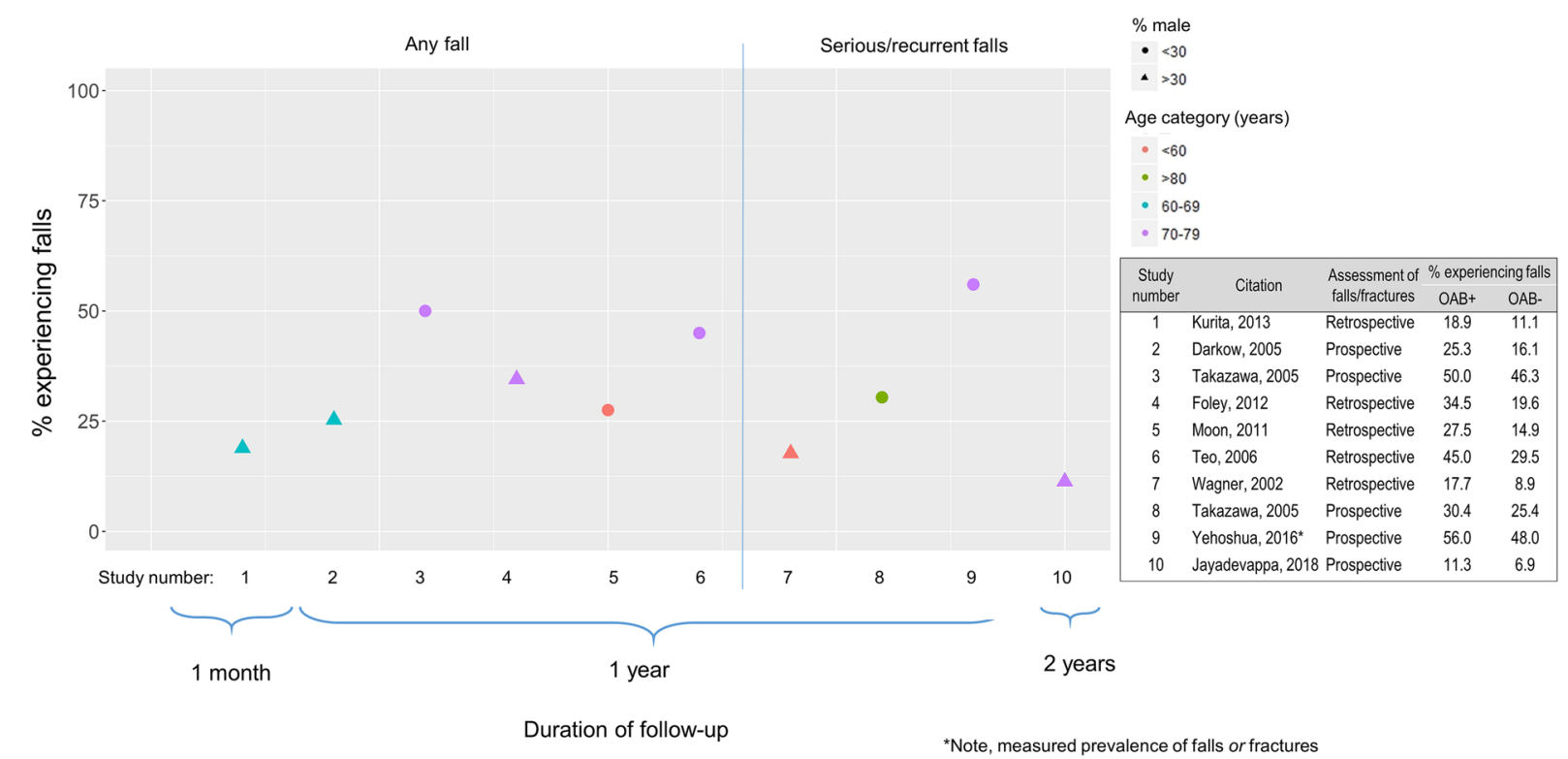

Fig. 2 Unadjusted estimates of the risk of falls among those with OAB, according to mean age and the percentage male of the sample

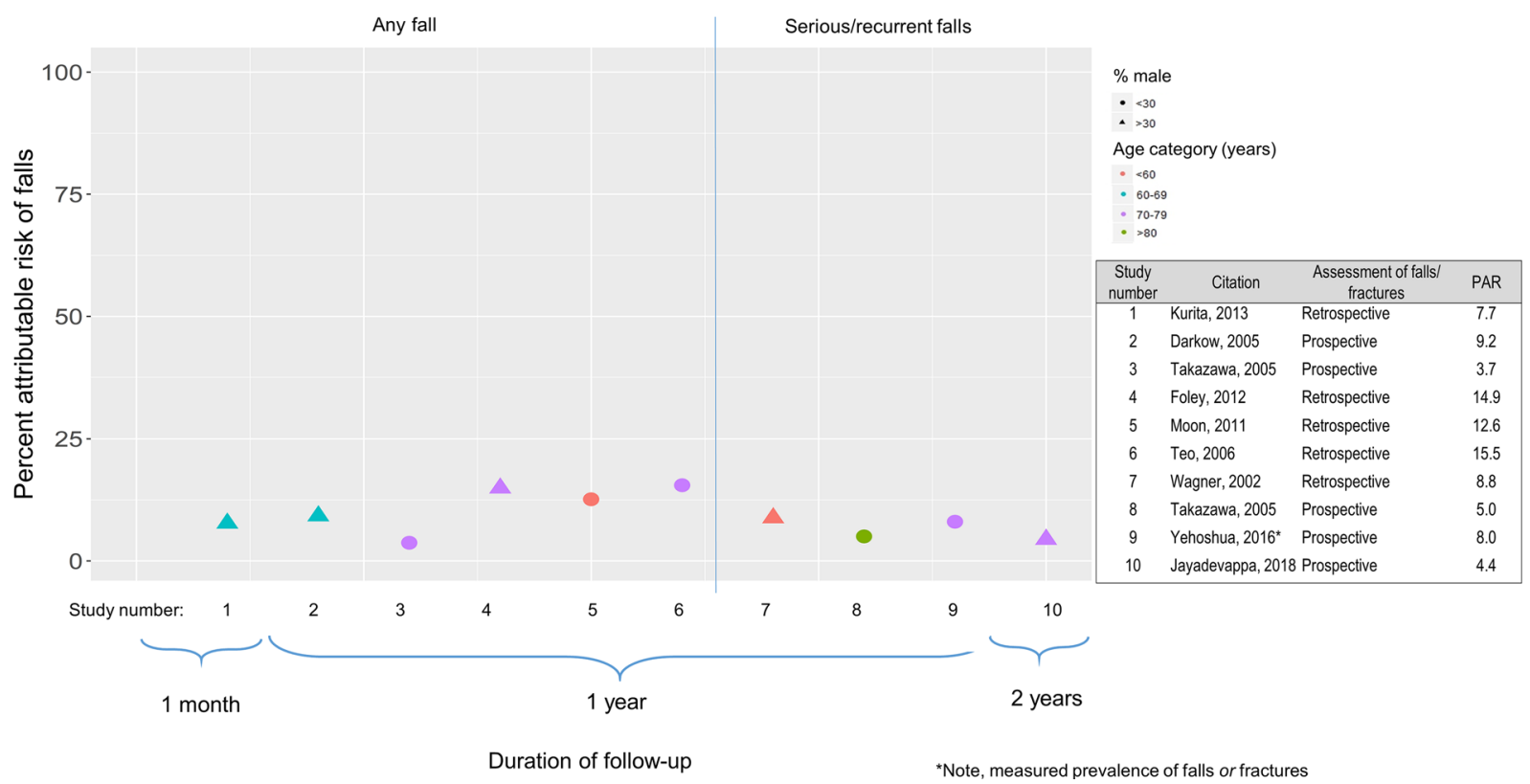

Fig. 3 Unadjusted estimates of the percent attributable risk of falls associated with $O A B$, by mean age and the percentage male of the sample

fracture was slightly higher among individuals with $\mathrm{OAB}$ who had been prescribed an antimuscarinic (3.01) compared to those who had not been prescribed an antimuscarinic (2.77) [28].
Ten studies reported adjusted estimates of the risk of any fall, or serious or recurrent falls, among those with $\mathrm{OAB}$ compared to those without OAB; and again, one of those studies [9] reported two sets of estimates (for at least one 
fall and for recurrent [two or more] falls) $[8,9,12,19,21,24-26,29]$. While studies consistently adjusted for age and sex, other significant risk factors varied across studies. Of the studies reporting adjusted risk of any falls, there was an increased risk associated with $\mathrm{OAB}$, with estimates ranging from a 1.3- to 2.3-fold. One study did not show an increased risk, but had a very small sample size $(n=26$; Fig. 4$)$ [9]. Two studies reporting on serious or recurrent falls showed a $40-60 \%$ increased risk associated with OAB. Two studies, one of which was by Gomes et al., looked specifically at the impact of $\mathrm{OAB}$ treatment on risk of falls. No difference in risk of serious falls was observed over 3 months between patients with $\mathrm{OAB}$ treated with tolterodine vs. oxybutynin (odds ratio [OR] 1.04 $[0.95,1.14])[20]$; and $\mathrm{OAB}$ therapy may be slightly protective of the risk of falls (OR 0.88
$[0.80,0.98])$ vs. not receiving $\mathrm{OAB}$ treatment [29].

Only one study reported unadjusted risk of fractures among those with $\mathrm{OAB}$ compared to those without OAB. That study, based on selfreported fractures in the preceding year, reported a 5\% risk of any fracture among those with $\mathrm{OAB}$ versus a $2.7 \%$ risk of any fracture in the non-OAB group, resulting in an unadjusted PAR of any fracture over 1 year of $2.3 \%$ [8].

Three studies reported adjusted risk of fractures among those with $\mathrm{OAB}$ compared to those without OAB. While point estimates of risk were consistently above 1.0 (range 1.3-1.5), estimates of increased risk were not significant for two of three studies (Fig. 4) $[8,22,27]$. No difference in risk of fractures was observed in either study that examined the impact of treatment [20, 28].

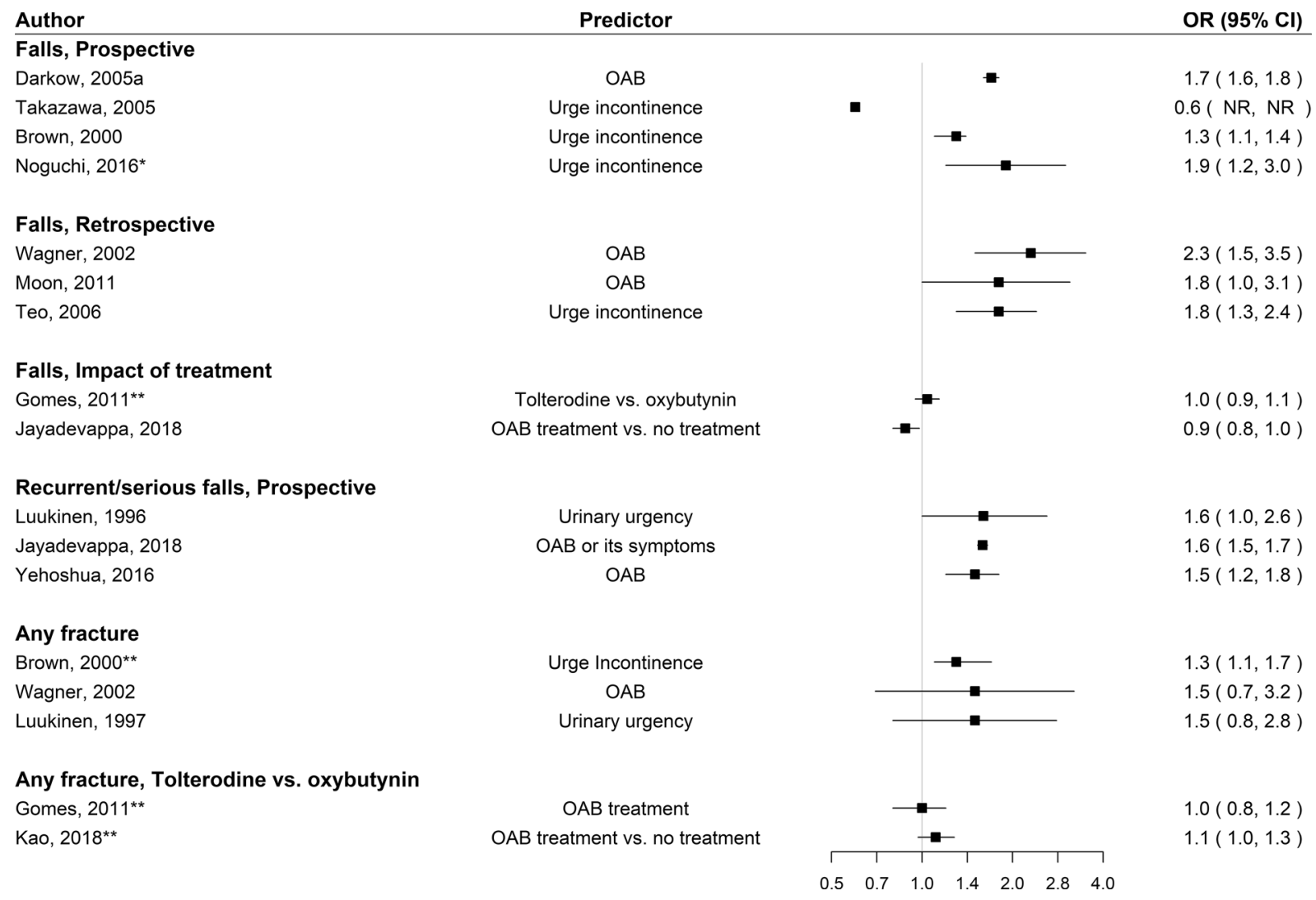

Fig. 4 Adjusted estimates of the risk of falls or fractures among those with OAB. *Presented incidence rate ratios rather than odds ratios. ${ }^{*}$ Presented hazard ratios rather than odds ratios 


\section{Sensitivity Analysis}

In sensitivity analyses, the population was broadened to include any incontinence or LUTS, comprising a wider range of symptoms related to $\mathrm{OAB}$ but that may not have been classified as OAB. In this population, unadjusted estimates of the risk of falls among those with incontinence or LUTS were elevated, but less than that observed among those with OAB. Overall, estimates were higher among samples that included older patients or had a higher percentage of women (Supplementary Fig. 1). Adjusted estimates continued to demonstrate an increased risk of falls associated with incontinence or LUTS, although less consistently than for OAB (Supplementary Fig. 2). For fractures, while point estimates from adjusted analyses generally suggested an increased risk associated with incontinence or LUTS, most confidence intervals spanned 1.0 (Supplementary Fig. 2).

\section{DISCUSSION}

While $\mathrm{OAB}$ and its constituent symptoms, particularly urgency and nocturia, are known risk factors for falls and fractures, the strength of the association is unclear because o variability in the designs and populations of studies contributing estimates of risk. This systematic review and synthesis of published estimates was performed to understand the range of estimates of falls and fractures associated with $\mathrm{OAB}$, and the impact of other factors on that risk. Samples with $\mathrm{OAB}$ had consistently elevated risks of falls and fractures compared to non-OAB samples; and the risk among those with $\mathrm{OAB}$ was higher with increasing age and proportion of women in the sample. Approximately one-quarter to one-half of patients with $\mathrm{OAB}$ were observed to fall annually, and adjusted estimates indicate a 1.3- to 2.3-fold increased risk of falls compared to non-OAB samples. Analysis of serious and recurrent falls showed similar trends, but the magnitude of risk was less. While analysis of fractures showed elevated risk in terms of the point estimates, most studies were designed to estimate falls and were underpowered to detect significant differences in fractures. The sensitivity analyses of incontinence and LUTS showed consistent trends, but with greater variability in estimates, reflecting the greater variability in symptoms and sample characteristics within those studies. These findings extend beyond older systematic reviews that considered a more limited range of fall-related outcomes [10], or urinary symptoms, and did not specifically focus on $\mathrm{OAB}$ or its treatments [11], which consistently reported increased risks of falls and fractures among those with other urinary symptoms $[10,11]$.

The findings from this study highlight both the strength of the relationship between $\mathrm{OAB}$ and falls and fractures, and the limited evidence of the impact of any treatment on that risk. In the core analysis, only two studies reported treatment status among cohorts examined for falls and fractures. One compared outcomes over 3 months and found no difference in serious falls among those initiating tolterodine vs. oxybutynin [20], although the time horizon was too short to observe serious falls or fractures and an untreated cohort was not included. The other study noted a slightly protective effect of $\mathrm{OAB}$ treatment on falls [OR $0.88(0.80,0.98)]$, but the exact nature of the $\mathrm{OAB}$ treatment was unspecified [29]. In the included study by Yehoshua et al. which compared outcomes among non-OAB patients and $\mathrm{OAB}$ patients who had initiated treated with anticholinergics, it was reported that the $\mathrm{OAB}$ patients were at $46 \%$ higher adjusted risk of falls or fractures, and a higher economic burden resulted; because all $O A B$ patients in this study were receiving treatment, it was not possible to isolate the effects of treatment from the effects of $\mathrm{OAB}$, although it is notable that the increased risk of falls or fractures persisted following any symptom control conferred by the antimuscarinic treatment [12]. A recent systematic review of the impact of continence management strategies, including pharmacotherapy for $\mathrm{OAB}$, on falls risk also identified little evidence that such strategies reduce falls, and acknowledged that the increased falls risk associated with anticholinergic medications could counter any observed benefits of continence management strategies in decreasing falls in this population [55]. 
While the findings of this review support the significant association between $\mathrm{OAB}$ and falls and fractures, substantial variability in estimates of risk was observed even after adjustment for other known risk factors. Risk varied according to age and sex of the sample but would have also varied according to the comorbidity burden or presence of other risk factors for falls, which were reported inconsistently across studies. The range in estimates observed highlight the challenges of disentangling the impact of $\mathrm{OAB}$ from that of other comorbid conditions and age. While estimates varied considerably by age and sex, the unadjusted PAR estimates were fairly consistent across studies, suggesting that while fall and fracture rates rise with older age and the proportion of the sample that is female, the additive effect of $\mathrm{OAB}$ remains constant across age and sex categories.

\section{Strengths and Limitations}

Strengths of this study included the application of rigorous systematic review methods to gathering the evidence base. While the core analysis was restricted to those with diagnosed $\mathrm{OAB}$, the sensitivity analysis allowed the inclusion of individuals with a wider range of OAB-related symptoms. Multiple measures of falls and fractures were considered, as were multiple types of estimates of risk. This study has limitations, largely dictated by the quality of the design and extent of reporting of the original articles. As a result of the nature of the research question, the present study was limited to observational studies, which are subject to various biases and different methods of defining OAB cases and/or outcome assessment. Despite being limited by variability across study designs, after assessing the quality of the included studies, the overall quality was considered to be good, with most studies fulfilling more than $50 \%$ of the STROBE criteria. Other risk factors for falls and fractures were inconsistently reported across studies, and hampered both the comparison of estimates and the isolation of specific impacts due to $\mathrm{OAB}$ from other comorbid conditions. Heterogeneity in study designs and sample characteristics prevented a meta-analysis of falls risk. Variable time horizons were employed across studies and fall and fracture rates could not be annualized. While every effort was made to identify all relevant publications, there may be some published data describing the risk of falls or fractures in $\mathrm{OAB}$ patients that were not identified and thus not included in the analysis. Although not examined here, as there is evidence that $\mathrm{OAB}$ is associated with frailty in older adults [56], and that frailty may be a risk factor for falls [57], an examination of the role of frailty status as a predictor of falls and fractures may be warranted. Unfortunately, as previously mentioned, as a result of inconsistent reporting of risk factors across included studies, this was not examined in the present study.

\section{CONCLUSION}

With the growing number of older adults worldwide, the clinical and economic impact of serious falls and fractures will likely continue to grow. Understanding the contribution of modifiable risk factors therefore becomes crucial. Even after adjustment for other risk factors, $\mathrm{OAB}$ remains an important and potentially modifiable risk factor. However, the risk directly attributable to $\mathrm{OAB}$ and the impact of medication use remains unclear. Evidence from the published literature clearly demonstrates the importance of $\mathrm{OAB}$ and its symptoms as risk factors for falls and fractures.

\section{ACKNOWLEDGEMENTS}

Funding. This study, article processing charges and Open Access fee were funded by the sponsor, Astellas. All authors had full access to all of the data in this study and take complete responsibility for the integrity of the data and accuracy of the data analysis.

Authorship. All named authors meet the International Committee of Medical Journal Editors (ICMJE) criteria for authorship for this article, take responsibility for the integrity of 
the work as a whole, and have given their approval for this version to be published.

Authorship Contributions. All others contributed to the study concept and design. Shelagh M. Szabo and Karissa M. Johnston were responsible for the acquisition of data. All authors contributed to the analysis and interpretation of data. Shelagh M. Szabo was responsible for the drafting of the manuscript. All authors contributed to the critical review and editing of the manuscript.

Disclosures. Shelagh M. Szabo is an employee of Broadstreet Health Economics and Outcomes Research (HEOR), a company contracted by Astellas to conduct this study. Karissa M. Johnston is an employee of Broadstreet Health Economics and Outcomes Research (HEOR), a company contracted by Astellas to conduct this study. Katherine L. Gooch was an employee of Astellas at the time of study completion. She is now an employee of Sarepta Therapeutics. David R. Walker is an employee of Astellas. Adrian S. Wagg acted as a consultant to Broadstreet HEOR.

Compliance with Ethics Guidelines. This article is based on previously conducted studies and does not contain any studies with human participants or animals performed by any of the authors.

Open Access. This article is distributed under the terms of the Creative Commons Attribution-NonCommercial 4.0 International License (http://creativecommons.org/licenses/ by-nc/4.0/), which permits any noncommercial use, distribution, and reproduction in any medium, provided you give appropriate credit to the original author(s) and the source, provide a link to the Creative Commons license, and indicate if changes were made.

\section{REFERENCES}

1. Stewart RB, Moore MT, May FE, Marks RG, Hale WE. Nocturia: a risk factor for falls in the elderly. J Am Geriatr Soc. 1992;40(12):1217-20.
2. Deandrea S, Lucenteforte E, Bravi F, Foschi R, La Vecchia C, Negri E. Risk factors for falls in community-dwelling older people: a systematic review and meta-analysis. Epidemiology. 2010;21(5):658-68.

3. Florence CS, Bergen G, Atherly A, Burns E, Stevens J, Drake C. Medical costs of fatal and nonfatal falls in older adults. J Am Geriatr Soc. 2018;66(4):693-8.

4. Faulkner KA, Cauley JA, Studenski SA, et al. Lifestyle predicts falls independent of physical risk factors. Osteoporos Int. 2009;20(12):2025-34.

5. Wein AJ, Rovner ES. Definition and epidemiology of overactive bladder. Urology. 2002;60(5 Suppl 1):7-12 (discussion).

6. Kurita N, Yamazaki S, Fukumori N, et al. Overactive bladder symptom severity is associated with falls in community-dwelling adults: LOHAS study. BMJ Open. 2013;3(5).

7. Tinetti ME, Speechley M, Ginter SF. Risk factors for falls among elderly persons living in the community. N Engl J Med. 1988;319(26):1701-7.

8. Wagner TH, Hu TW, Bentkover J, et al. Health-related consequences of overactive bladder. Am J Manag Care. 2002;8(19 Suppl):S598-607.

9. Takazawa K, Arisawa K. Relationship between the type of urinary incontinence and falls among frail elderly women in Japan. J Med Invest. 2005; 52(3-4):165-71.

10. Chiarelli PE, Mackenzie LA, Osmotherly PG. Urinary incontinence is associated with an increase in falls: a systematic review. Aust J Physiother. 2009;55(2):89-95.

11. Noguchi N, Chan L, Cumming RG, Blyth FM, Naganathan V. A systematic review of the association between lower urinary tract symptoms and falls, injuries, and fractures in community-dwelling older men. Aging Male. 2016:1-7.

12. Yehoshua A, Chancellor M, Vasavada S, et al. Health resource utilization and cost for patients with incontinent overactive bladder treated with anticholinergics. J Manag Care Spec Pharm. 2016;22(4):406-13.

13. Marcum ZA, Perera S, Thorpe JM, et al. Anticholinergic use and recurrent falls in communitydwelling older adults: findings from the health $\mathrm{ABC}$ study. Ann Pharmacother. 2015;49(11):1214-21.

14. Zia A, Kamaruzzaman S, Myint PK, Tan MP. Anticholinergic burden is associated with recurrent and injurious falls in older individuals. Maturitas. 2016;84:32-7. 
15. Crispo JA, Willis AW, Thibault DP, et al. Associations between anticholinergic burden and adverse health outcomes in Parkinson disease. PLoS One. 2016;11(3):e0150621.

16. Richardson K, Bennett K, Maidment ID, Fox C, Smithard D, Kenny RA. Use of medications with anticholinergic activity and self-reported injurious falls in older community-dwelling adults. J Am Geriatr Soc. 2015;63(8):1561-9.

17. Hunter KF, Wagg A, Kerridge T, Chick H, Chambers T. Falls risk reduction and treatment of overactive bladder symptoms with antimuscarinic agents: a scoping review. Neurourol Urodyn. 2011;30(4): 490-4.

18. von Elm E, Altman DG, Egger $M$, et al. The strengthening the reporting of observational studies in epidemiology (STROBE) statement: guidelines for reporting observational studies. Lancet. 2007;370(9596):1453-7.

19. Darkow T, Fontes CL, Williamson TE. Costs associated with the management of overactive bladder and related comorbidities. Pharmacotherapy. $2005 ; 25(4): 511-9$.

20. Gomes T, Juurlink DN, Ho JMW, Schneeweiss S, Mamdani MM. Risk of serious falls associated with oxybutynin and tolterodine: a population based study. J Urol. 2011;186(4):1340-4.

21. Luukinen H, Koski K, Kivela SL, Laippala P. Social status, life changes, housing conditions, health, functional abilities and life-style as risk factors for recurrent falls among the home-dwelling elderly. Public Health. 1996;110(2):115-8.

22. Luukinen H, Koski K, Laippala P, Kivela SL. Factors predicting fractures during falling impacts among home-dwelling older adults. J Am Geriatr Soc. 1997;45(11):1302-9.

23. Foley AL, Loharuka S, Barrett JA, et al. Association between the geriatric giants of urinary incontinence and falls in older people using data from the Leicestershire MRC incontinence study. Age Ageing. 2012;41(1):35-40.

24. Moon SJ, Kim YT, Lee TY, et al. The influence of an overactive bladder on falling: a study of females aged 40 and older in the community. Int Neurourol J. 2011;15(1):41-7.

25. Teo JS, Briffa NK, Devine A, Dhaliwal SS, Prince RL. Do sleep problems or urinary incontinence predict falls in elderly women? Aust J Physiother. 2006;52(1):19-24.

26. Noguchi N, Chan L, Cumming RG, et al. Lower urinary tract symptoms and incident falls in community dwelling older men: the concord health and ageing in men project. J Urol. 2016;196(6):1694-9.

27. Brown JS, Vittinghoff E, Wyman JF, et al. Urinary incontinence: does it increase risk for falls and fractures? Study of Osteoporotic Fractures Research Group. J Am Geriatr Soc. 2000;48(7):721-5.

28. Kao LT, Huang CY, Lin HC, Chu CM. No increased risk of fracture in patients receiving antimuscarinics for overactive bladder syndrome: a retrospective cohort study. J Clin Pharmacol. 2018;58(6):727-32.

29. Jayadevappa R, Chhatre S, Newman DK, Schwartz JS, Wein AJ. Association between overactive bladder treatment and falls among older adults. Neurourol Urodyn. 2018. https://doi.org/10.1002/nau.23719.

30. Nakagawa H, Niu K, Hozawa A, et al. Impact of nocturia on bone fracture and mortality in older individuals: a Japanese longitudinal cohort study. J Urol. 2010;184(4):1413-8.

31. Nevitt MC, Cummings SR, Kidd S, Black D. Risk factors for recurrent nonsyncopal falls. A prospective study. JAMA. 1989;261(18):2663-8.

32. Parsons JK, Mougey J, Lambert L, et al. Lower urinary tract symptoms increase the risk of falls in older men. BJU Int. 2009;104(1):63-8.

33. Stenhagen M, Ekstrom H, Nordell E, Elmstahl S. Falls in the general elderly population: a 3-and 6-year follow-up of risk factors using data from the longitudinal population study "good ageing in Skane”. Eur Geriatr Med. 2012;3:S53.

34. Temml C, Ponholzer A, Gutjahr G, Berger I, Marszalek M, Madersbacher S. Nocturia is an ageindependent risk factor for hip-fractures in men. Neurourol Urodyn. 2009;28(8):949-52.

35. Tromp AM, Pluijm SM, Smit JH, Deeg DJ, Bouter LM, Lips P. Fall-risk screening test: a prospective study on predictors for falls in community-dwelling elderly. J Clin Epidemiol. 2001;54(8):837-44.

36. Tromp AM, Smit JH, Deeg DJH, Bouter LM, Lips P. Predictors for falls and fractures in the longitudinal aging study Amsterdam. J Bone Miner Res. 1998;13(12):1932-9.

37. Van Helden S, Wyers CE, Dagnelie PC, et al. Risk of falling in patients with a recent fracture. BMC Musculoskeletal Disorders. 2007;8(55).

38. Vaughan CP, Brown CJ, Goode PS, Burgio KL, Allman RM, Johnson ITM. The association of nocturia with incident falls in an elderly community-dwelling cohort. Int J Clin Pract. 2010;64(5):577-83. 
39. Wu M, Hsu Y, Wang J, Su T. Do lower urinary tract symptoms (LUTS) predispose the individuals to more admissions in Taiwanese women?-a preliminary report. Neurourol Urodyn. 2012;31(6):1001-2.

40. Asplund R. Hip fractures, nocturia, and nocturnal polyuria in the elderly. Arch Gerontol Geriatr. 2006;43(3):319-26.

41. Cesari M, Landi F, Torre S, Onder G, Lattanzio F, Bernabei R. Prevalence and risk factors for falls in an older community-dwelling population. J Gerontol Ser A Biol Sci Med Sci. 2002;57(11):M722-6.

42. de Rekeneire N, Visser M, Peila R, et al. Is a fall just a fall: correlates of falling in healthy older persons. The Health, Aging and Body Composition Study. J Am Geriatr Soc. 2003;51(6):841-6.

43. Endeshaw Y. Correlates of self-reported nocturia among community-dwelling older adults. J Gerontol A Biol Sci Med Sci. 2009;64(1):142-8.

44. Galizia G, Langellotto A, Cacciatore F, et al. Association between nocturia and falls-related longterm mortality risk in the elderly. J Am Med Dir Assoc. 2012;13(7):640-4.

45. Hedman AM, Fonad E, Sandmark H. Older people living at home: associations between falls and health complaints in men and women. J Clin Nurs. 2013;22(19-20):2945-52.

46. Huang HC. A checklist for assessing the risk of falls among the elderly. J Nurs Res. 2004;12(2):131-42.

47. Johansson C, Hellstrom L, Ekelund P, Milsom I. Urinary incontinence: a minor risk factor for hip fractures in elderly women. Maturitas. 1996; 25(1):21-8.

48. Lee PG, Cigolle C, Blaum C. The co-occurrence of chronic diseases and geriatric syndromes: the health and retirement study. J Am Geriatr Soc. 2009;57(3):511-6.
49. Moreira MD, Costa AR, Rodrigues Felipe L, Caldas $\mathrm{CP}$. The association between nursing diagnoses and the occurrence of falls observed among elderly individuals assisted in an outpatient facility. Rev Lat Am Enfermagem. 2007;15(2):311-7.

50. Rosso AL, Eaton CB, Wallace R, et al. Geriatric syndromes and incident disability in older women: results from the women's health initiative observational study. J Am Geriatr Soc. 2013;61(3):371-9.

51. Yasumura S, Haga H, Nagai H, Suzuki T, Amano H, Shibata H. Rate of falls and the correlates among elderly people living in an urban community in Japan. Age Ageing. 1994;23(4):323-7.

52. Marshall LM, Lapidus JA, Wiedrick J, et al. Lower urinary tract symptoms and risk of nonspine fractures among older community dwelling U.S. men. J Urol. 2016;196(1):166-72.

53. Schluter PJ, Arnold EP, Jamieson HA. Falls and hip fractures associated with urinary incontinence among older men and women with complex needs: a national population study. Neurourol Urodyn. 2018;37(4):1336-43.

54. Sohn KL, Shin J, Lee CK. Association between female urinary incontinence and geriatric health problems: results from Korean Longitudinal Study of Ageing (2006). Korean J Fam Med. 2018;39(1):5.

55. Batchelor FA, Dow B, Low MA. Do continence management strategies reduce falls? a systematic review. Australas J Ageing. 2013;32(4):211-6.

56. Suskind AM, Quanstrom K, Zhao S, et al. Overactive bladder is strongly associated with frailty in older individuals. Urology. 2017;106:26-31.

57. de Vries OJ, Peeters GM, Lips P, Deeg DJ. Does frailty predict increased risk of falls and fractures? A prospective population-based study. Osteoporos Int. 2013;24(9):2397-403. 